\title{
LETTER
}

\section{Cell-free DNA as a promising marker for risk stratification of pulmonary embolism}

\author{
Evandro M Neto-Neves
}

Please see related research by Arnalich et al., http://ccforum.com/content/17/3/R90

Arnalich and colleagues reported an interesting clinical study that evaluated cell-free plasma mitochondrial and nuclear DNA concentrations in patients with pulmonary embolism (PE) [1]. They found increased circulating mitochondrial and nuclear DNA levels, as well as alterations in other cardiac biomarkers (heart-type fatty acidbinding protein and troponin I) in patients with massive PE compared with those found in patients with submassive PE [1]. Importantly, all these biomarkers were found at higher concentrations in fatal massive PE than in nonfatal PE [1].

I would like to add experimental information associating cell-free DNA and acute pulmonary thromboembolism (APT). Experimental evidence showed that cell-free DNA concentrations increase in proportion to the severity of experimental APT [2]. In addition, these previous findings suggest that lysed cells from the thrombi are probably the major source of increased circulating plasma DNA in experimental APT. Supporting this idea, microsphere-induced PE causing similar pulmonary hypertension to that induced by APT did not result in increased plasma DNA concentrations. Moreover, blood clots release free DNA in a dose-dependent manner in vitro [2]. Although Arnalich and colleagues have not specified the main causes of PE in their study, it is possible that part of measured free DNA may derive from thrombi causing PE.

In conclusion, the clinical findings reported by Arnalich and colleagues align with previous experimental results showing that plasma DNA levels increase with severity of APT. While circulating DNA has emerged as a promising marker for risk stratification of $\mathrm{PE}$, further investigations are needed to clarify the origins of free DNA.

\section{Authors' response \\ Francisco Arnalich, Maria Constanza Maldifassi, Enrique Ciria, Rosa Codoceo, Jaime Renart, Carmen Fernández-Capitán, Rafael Herruzo, Francisco Garcia-Rio, Eduardo López-Collazo, Carmen Montiel}

Dr Neto-Neves, in his letter on our paper published in the May issue of Critical Care [1], suggests correctly that a potential source of the high amounts of cell-free plasma mitochondrial DNA and nuclear DNA observed in our patients with massive PE could be thrombi obstructing the pulmonary vessels. With regards to his comment about the main causes of PE in our study, he does not realize that Table 1 indicates the main predisposing risk factors and shows that 16 patients developed deep venous thrombosis.

Although thrombi are probably the origin of increased circulating DNA concentration in the model of

\footnotetext{
Correspondence: evandronetoneves@yahoo.com.br

Department of Emergency Medicine, Indiana University School of Medicine,

635 Barnhill Drive, Medical Science Building, Room 371, Indianapolis, IN 46202, USA
}

experimental acute PE reported by Uzuelli and colleagues [2], two main findings in our study indicate that acute right ventricular damage could more probably be the main source of DNA. Firstly, highly significant direct associations were found between plasma heart-type fatty acid-binding protein concentrations and both plasma mitochondrial DNA and nuclear DNA levels. Heart-type fatty acid-binding protein may be elevated in our patients as a consequence of right ventricular pressure overload, which increases wall stress resulting in right ventricular ischemia and infarction [3]. Secondly, the significant correlation between plasma soluble Fas values, an indirect marker of apoptotic cell death, and mitochondrial DNA concentrations observed in this study could be a direct consequence of the hypoxia-induced 
apoptosis of cardiomyocytes, which is known to occur mainly via the mitochondrial pathway of apoptosis [4]. Similarly, in bacteremic patients, a potential relationship between high plasma cell-free nuclear DNA concentration and apoptotic DNA fragmentation has been reported recently [5].

\section{Abbreviations}

APT: Acute pulmonary thromboembolism; PE: Pulmonary embolism.

\section{Competing interests}

The authors declare that they have no competing interests.

Published: 19 Nov 2013

\section{References}

1. Arnalich F, Maldifassi MC, Ciria E, Codoceo R, Renart J, Fernandez-Capitan C, Herruzo R, Garcia-Rio F, Lopez-Collazo E, Montiel C: Plasma levels of mitochondrial and nuclear DNA in patients with massive pulmonary embolism in the emergency department: a prospective cohort study. Crit Care 2013, 17:R90.

2. Uzuelli JA, Dias-Junior CA, Izidoro-Toledo TC, Gerlach RF, Tanus-Santos JE: Circulating cell-free DNA levels in plasma increase with severity in experimental acute pulmonary thromboembolism. Clin Chim Acta 2009, 409:112-116.

3. Yellow DM, Hausenloy DJ: Myocardial reperfusion injury. N Engl J Med 2007, 357:1121-1135.

4. Liu T, Laurell C, Selivanova G, Lundeberg J, Nilsson P, Wiman KG: Hypoxia induces p53-dependent transactivation and Fas/CD95-dependent apoptosis. Cell Death Differ 2007, 14:411-421.

5. Huttunen R, Kuparinen T, Jylhäva J, Aittoniemi J, Vuento R, Huhtala H, Laine J, Syrjänen J, Hurme M: Fatal outcome in bacteremia is characterized by high plasma cell free DNA concentration and apoptotic DNA fragmentation: a prospective cohort study. PLOS One 2011, 6:e21700.

$10.1186 / \operatorname{cc} 13118$

Cite this article as: Neto-Neves: Cell-free DNA as a promising marker for risk stratification of pulmonary embolism. Critical Care

2013, 17:464 